\title{
CARACTERIZAÇÃO DA CADEIA PRODUTIVA DA PECUÁRIA LEITEIRA EM RONDON DO PARÁ, PARÁ, BRASIL
}

SOARES,Bruno Cabral ${ }^{1}$

LOURENÇO JÚNIOR, José de Brito ${ }^{2}$

SANTOS, Marcos Antônio Souza dos ${ }^{1}$

SENA, Ana Laura dos Santos ${ }^{3}$

RODRIGUES FILHO, José Adérito ${ }^{4}$

SANTANA, Antônio Cordeiro de $\mathrm{de}^{5}$

HOMMA, Alfredo Kingo Oyama ${ }^{6}$

MACIEL E SILVA, André Guimarães ${ }^{7}$

ANDRADE, Stefano Juliano Tavares $\mathrm{de}^{7}$

RESUMO: O artigo caracteriza a cadeia produtiva da pecuária leiteira no município de Rondon do Pará, localizado no Sudeste Paraense. Os dados foram obtidos a partir de entrevistas com os principais atores locais que atuam nessa cadeia produtiva. Os resultados indicam que apesar do rebanho bovino se manter relativamente estável nos últimos anos, a produção de leite bovino tem diminuído, evidenciando que os produtores estão se especializando em pecuária de corte, e que a pecuária leiteira está cedendo espaço para outras atividades como a produção de grãos e o reflorestamento que estão em expansão nessa região. Outros fenômenos que também estão contribuindo para esse contexto são o envelhecimento das populações do meio rural, escassez de mão de obra, infraestrutura precária de estradas e de acesso à energia elétrica, além da baixa capilaridade dos serviços de assistência técnica e extensão rural. A persistência de sistemas de produção de baixo nível tecnológico implica em baixa produtividade animal e baixa qualidade do produto comercializado, o que pode manter a tendência declinante da produção e inviabilizar a atividade no longo prazo. Uma maior articulação entre os atores dessa cadeia produtiva em âmbito local é condição fundamental para enfrentar as limitações atuais, contribuindo para o desenvolvimento de uma pecuária leiteira mais eficiente e sustentável.

Palavras chave: Bovinocultura de leite. Sistemas de produção. Tecnologia. Mercado. Amazônia.

\section{CHARACTERIZATION OF DAIRY FARMING PRODUCTIVE CHAIN IN RONDON DO PARÁ, BRAZIL}

\footnotetext{
SUMMARY: The article describes the Dairy Farming Productive Chain in the Municipality of Rondon do Pará, located in the Southeastern part of the state of Pará. The data were obtained from interviews with important local players who work in this productive chain. The results indicate that, although the cattle herd size has remained relatively stable for the last few years, milk production had decreased, showing that farmers are concentrating on meat production, and that milk production is being substituted by other activities such as grain production and reforestation that has largely expanded in the region. Other phenomena that has also contributed to this context in the rural areas include population aging, labor shortage, poor road and energy infrastructure, as well as low technical assistance and rural extension. The persistence of production systems with poor technology results in both low

${ }^{1}$ Médico Veterinário, Doutor em Ciência Animal, Professor da Universidade Federal Rural da Amazônia (UFRA)

${ }^{2}$ Engenheiro Agrônomo, Doutor em Ciências Biológicas, Professor do Programa de Pós-graduação em Ciência

Animal da UFPA

${ }^{3}$ Economista, Doutora em Desenvolvimento Socioambiental, Pesquisadora da Embrapa Amazônia Oriental

${ }^{4}$ Engenheiro Agrônomo, Mestre em Zootecnia, Pesquisador da Embrapa Amazônia Oriental

${ }^{5}$ Engenheiro Agrônomo, Doutor em Economia Rural, Professor da Universidade Federal Rural da Amazônia

${ }^{6}$ Engenheiro Agrônomo, Doutor em Economia Rural, Pesquisador da Embrapa Amazônia Oriental

${ }^{7}$ Médico Veterinário, Doutor em Zootecnia, Professor da Universidade Federal do Pará (UFPA)
} 
animal production and in quality of products available for sale, which may maintain a declining tendency of production in the long term. A greater articulation among players in this local productive chain is fundamental to face current limitations for development of a more efficient and sustainable dairy farming.

Keywords: Dairy farming. Production systems. Technology. Market. Amazon.

\section{INTRODUÇÃO}

Na Amazônia, a pecuária leiteira vem evoluindo substancialmente nas três últimas décadas, impulsionada pelas oportunidades de mercado a partir da implantação de agroindustrias em regiões de fronteira, possibilidade de ser desenvolvida em sistemas produtivos mistos (carne e leite), capacidade de gerar produção e renda com certa estabilidade ao longo do ano, e pela disponibilidade de políticas de crédito de fomento. Esse contexto tornou a atividade atrativa para a agricultura familiar amazônica que necessita de alternativas produtivas com essas características (SANTOS et al., 2014a; SANTOS et al., 2014b).

O estado do Pará é o segundo maior produtor de leite bovino da região, respondendo por 30,94\% do total produzido. Entre os dez municípios considerados maiores produtores, nove estão localizados no sudeste paraense, o que faz dessa mesorregião a maior bacia leiteira do estado, com 71,34\% do total produzido (IBGE, 2015). Nessa mesorregião está localizado o municipio de Rondon do Pará, objeto de análise deste artigo.

A pecuária leiteira em Rondon do Pará é composta por pequenas unidades de produção, com gestão e uso de mão de obra familiar em sistemas diversificados, combinando agricultura e pecuária (SOARES et al., 2013). É uma atividade importante em termos socioeconômicos, pois envolve a utilização de um significativo número de trabalhadores ao longo da cadeia produtiva, além de impactar na geração de recursos públicos, através da captação de tributos, o que evidencia a importância da cadeia leiteira na geração de emprego e renda e no impulso ao desenvolvimento socioeconômico (VIANA;FERRAS, 2007).

A análise da cadeia produtiva da pecuária leiteira possibilita o acompanhamento do produto, durante a produção, processamento e comercialização, o que permite identificar pontos fortes, pontos fracos, ameaças e oportunidades de desenvolvimento, constituindo-se em ferramenta importante para tomada de decisão dos agentes econômicos envolvidos, além de promover incentivo ao crescimento da produção e da qualidade do produto ofertado. Assim, objetivou-se com o presente trabalho caracterizar a cadeia produtiva da pecuária leiteira no município de Rondon do Pará, estado do Pará. 


\section{METODOLOGIA}

\section{ÁREA DE ESTUDO}

O trabalho foi desenvolvido no município de Rondon do Pará (S 04 46'45"/ W $48^{\circ}$ 04'00”), localizado ao longo da BR-222, antiga PA-70, a $80 \mathrm{~km}$ da rodovia Belém-Brasília, com uma distância de $570 \mathrm{~km}$ da capital, Belém-PA. Esse município se constitui como parte da mesorregião do Sudeste Paraense, na microrregião de Paragominas, apresentando uma população estimada em 46.964 habitantes, numa área de $8.247 \mathrm{~km}^{2}$. Possui clima do tipo Ami, com temperatura média de $26,35{ }^{\circ} \mathrm{C}$, apresentando a média máxima em torno de $32,01{ }^{\circ} \mathrm{C}$ e mínima de $22,71{ }^{\circ} \mathrm{C}$. A umidade relativa apresenta oscilações entre a estação mais chuvosa e a mais seca, que vão de 100 a 52\%, sendo a média real de 78\% (SOARES et al., 2013).

\section{COLETA DE DADOS}

Para analisar a cadeia da pecuária leiteira de Rondon do Pará foi necessário identificar a sua estrutura: (i) fornecimento de insumos, (ii) produção, (iii) processamento e comercialização e (iv) organizações e instituições de apoio. A produção envolve os pecuaristas de leite, responsáveis pela obtenção de insumos e execução de todas as práticas de manejo produtivo. Na etapa de processamento têm-se laticínios, responsáveis em agregar valor ao produto, e queijarias informais, instaladas nas próprias unidades produtoras. O fluxo de comercialização ocorre por meio de supermercados, padarias, restaurantes e hotéis, cuja finalidade é atender o consumidor final.

Além desses agentes a cadeia produtiva é influenciada pelos ambientes organizacional e institucional. O ambiente organizacional tem o objetivo de propiciar as condições para funcionamento das cadeias produtivas e envolve universidades, instituições de pesquisa, normalização, fiscalização, associações, cooperativas e sindicatos. O ambiente institucional é representado pelos costumes, culturas, etnias e tradições, fatores que estabelecem a diferença entre as unidades produtivas, capazes de influenciar o ambiente organizacional e envolver as políticas setoriais e macroeconômicas, o que reflete na modernização do setor, nas inovações tecnológicas e no comportamento das organizações (NORONHA et al., 2015; SANTANA; AMIN, 2002).

Após levantamento dos agentes que atuam na pecuária leiteira, foram realizadas entrevistas, com perguntas abertas, e roteiro organizado de acordo com a estrutura observada, de forma a atingir os diferentes atores envolvidos (NORONHA et al., 2015; SANTOS e SANTANA, 2014). Foram entrevistados produtores rurais, funcionários da Agência de Defesa 
Agropecuária do estado do Pará (ADEPARÁ), Empresa de Assistência Técnica e Extensão Rural do estado do Pará (EMATER-PA), gestores de bancos de fomento (Banco do Brasil e Banco da Amazônia), representantes das Secretarias Municipais de Agricultura e Meio Ambiente (SEMA), do Sindicato dos Trabalhadores e Trabalhadoras Rurais locais (STTR), Associação de Produtores Amigos do Leite (AMILEITE), Sindicato dos Produtores Rurais, proprietários de laticínios que atuam no município, equipe de inspeção municipal e nutricionista da Secretaria Municipal de Educação, responsável pela gestão da merenda escolar.

\section{RESULTADO E DISCUSSÃO}

\section{ESTRUTURA DA CADEIA PRODUTIVA}

Os elos da cadeia são apresentados conforme as etapas de produção, beneficiamento e distribuição. A produção envolve os pecuaristas de leite que adquirem diversos insumos produtivos de fornecedores à montante. Na etapa de beneficiamento têm-se laticínios, responsáveis em agregar valor ao produto, e queijarias clandestinas, instaladas nas fazendas. Por fim, o fluxo de comercialização por meio de supermercados, padarias, restaurantes e hotéis que atendem os consumidores (Figura 1). Essa estrutura detalhada na figura é utilizada para a exposição dos resultados e descrição da cadeia produtiva do leite no município de Rondon do Pará, estado do Pará.

Figura 1. Estrutura da cadeia produtiva da pecuária leiteira em Rondo do Pará, estado do Pará.

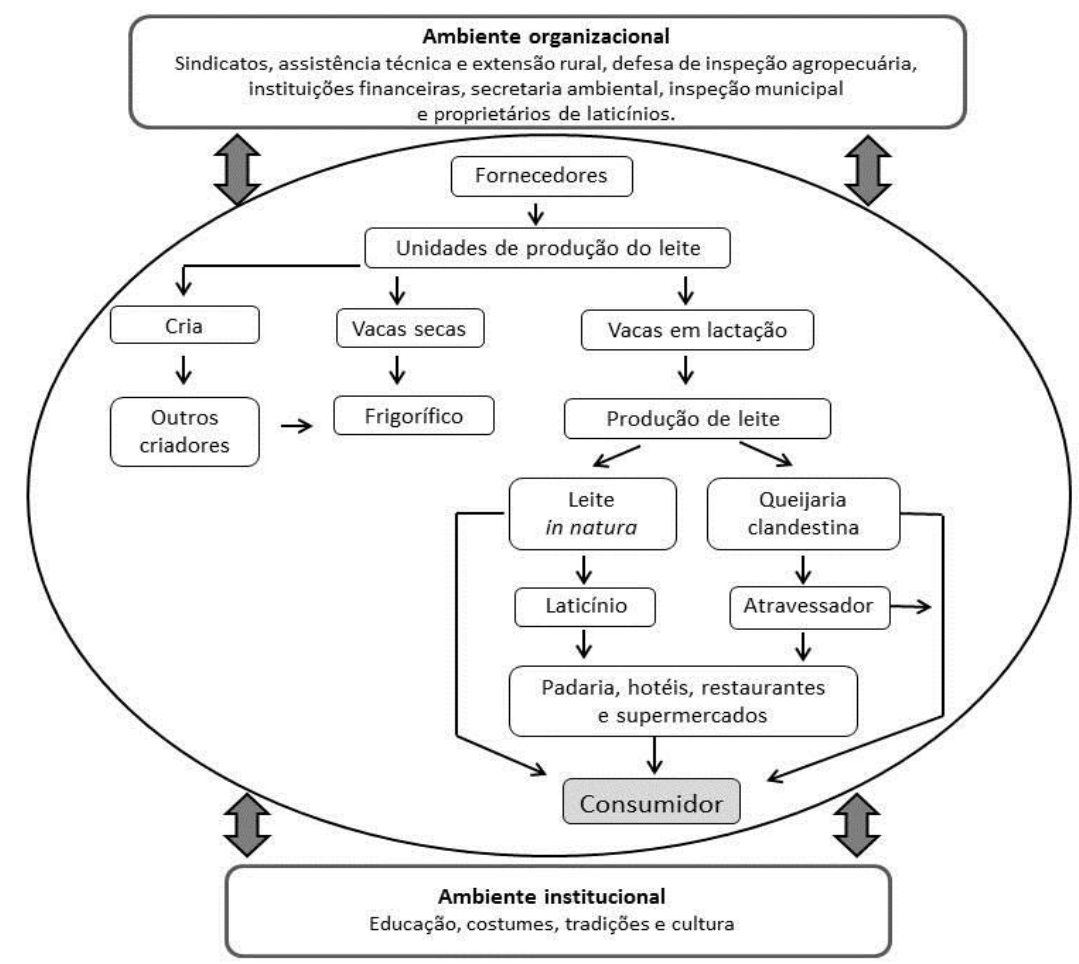




\section{PRODUÇÃO DE LEITE}

No estado do Pará, a mesorregião de maior importância para a atividade leiteira é o Sudeste Paraense, onde se destaca a microrregião de Paragominas, que engloba municípios de tradição na bovinocultura leiteira. O município de Rondon do Pará, atualmente, é responsável por 7,5\% da produção leiteira da microrregião de Paragominas (Tabela 1).

Tabela 1. Produção de leite (mil litros) do estado do Pará, microrregião de Paragominas e municípios, no período de 1990 a 2015.

\begin{tabular}{|c|c|c|c|c|c|c|c|c|}
\hline \multirow[b]{2}{*}{ Município } & \multicolumn{2}{|c|}{1990} & \multicolumn{2}{|c|}{2000} & \multicolumn{2}{|c|}{2010} & \multicolumn{2}{|c|}{2015} \\
\hline & $\begin{array}{c}\text { Mil } \\
\text { litros }\end{array}$ & $(\%)$ & $\begin{array}{c}\text { Mil } \\
\text { litros }\end{array}$ & $(\%)$ & $\begin{array}{c}\text { Mil } \\
\text { litros }\end{array}$ & $(\%)$ & $\begin{array}{c}\text { Mil } \\
\text { litros }\end{array}$ & $(\%)$ \\
\hline Abel Figueiredo & 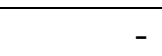 & - & 7.265 & 12,4 & 7.339 & 9,7 & 3.581 & 7,0 \\
\hline Ulianópolis & - & - & 1.350 & 2,3 & 3.265 & 4,3 & 5.301 & 10,4 \\
\hline Dom Eliseu & 5.061 & 8,9 & 3.455 & 5,9 & 7.170 & 9,5 & 1.726 & 3,4 \\
\hline Rondon do Pará & 13.716 & 24,0 & 7.674 & 13,1 & 18.604 & 24,6 & 3.851 & 7,5 \\
\hline Goianésia do Pará & - & - & 5.400 & 9,2 & 8.870 & 11,7 & 997 & 2,0 \\
\hline Bom Jesus do Tocantins & 3.200 & 5,6 & 8.237 & 14,1 & 12.514 & 16,5 & 16.897 & 33,1 \\
\hline Paragominas & 35.208 & 61,6 & 25.206 & 43,0 & 17.865 & 23,6 & 18.761 & 36,7 \\
\hline Total & 57.185 & 100,0 & 58.587 & 100,0 & 75.627 & 100,0 & 51.114 & 100,0 \\
\hline Estado do Pará & 231.497 & 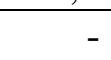 & 380.319 & 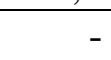 & 563.777 & 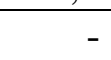 & 567.231 & - \\
\hline Microrregião de Paragominas & 57.185 & 24,7 & 58.587 & 15,4 & 75.627 & 13,4 & 51.114 & 9,0 \\
\hline
\end{tabular}

A pecuária leiteira de Rondon do Pará é caracterizada por pequenos produtores em que o núcleo de decisões, planejamento, gerência, trabalho e capital é controlado pela família. Em geral, são produtores com baixo nível de escolaridade, a maioria 56,36\%, possui apenas o ensino fundamental incompleto, e baixa renda, que para aproveitar as potencialidades da propriedade, e otimizar o uso da mão de obra disponível e aumentar sua renda, diversificam suas atividades com plantio de roça como arroz, feijão, mandioca e milho (SOARES et al., 2013).

A estrutura física das propriedades rurais é incipiente, sem instalações básicas ou então mal planejadas, são muito frequentes estábulos que geram grandes dificuldades na higienização, o que impossibilita o manejo adequado para o bom funcionamento do sistema. As áreas de pastagem são formadas predominantemente por braquiarão (Brachiaria brizantha cv. Marandu), e não há plantio de leguminosas ou consorciação da pastagem. Nenhum tipo de adubação é feito nessas áreas, apenas roçagem a cada dois anos em áreas com presença de pragas como a cigarrinha (Deois flavopicta) e lagarta (Macis latipes) e invasoras como lacre (Vismia guianensis), assa-peixe (Vernonanthura phosphorica) e vassourinha de botão (Espermacoce verticillata), entre outras. A suplementação mineral é feita em todas as propriedades, no entanto, 
sempre misturado com sal branco, e são poucos os que fazem uso de algum tipo de grão ou subprodutos de agroindústria.

O manejo do rebanho ocorre apenas para a separação das vacas em lactação, permanecendo o restante dos animais juntos. A reprodução ocorre através da monta natural, sem definir estação de monta e não são realizados exames andrológicos e diagnósticos de gestação. Quanto ao rebanho é constituído principalmente por animais cruzados de reprodutores de corte com as raças Indubrasil, Gir e Girolando, assim considerado de dupla aptidão, com os bezerros machos direcionados para a produção de carne.

Nos últimos anos, dados da ADEPARÁ (2016) indicam crescimento do efetivo bovino no município, entre 2011 e 2015, de 346.359 para 363.814, respectivamente (Tabela 2). Entretanto sem grandes avanços nos dois últimos anos, fato que evidência aptidão do município para bovinocultura.

Tabela 2. Efetivo do rebanho bovino, propriedades e número de cabeças por propriedade, Rondon do Pará, estado do Pará, 2011 a 2015.

\begin{tabular}{ccc}
\hline Ano & $\mathbf{N}^{\mathbf{0}}$ de propriedades & Efetivo (cabeças) \\
\hline 2011 & 965 & 346.359 \\
2012 & 1.604 & 331.121 \\
2013 & 1.704 & 363.970 \\
2014 & 1.702 & 365.086 \\
2015 & 1.748 & 363.814 \\
\hline
\end{tabular}

Fonte: ADEPARÁ (2016).

Com relação à composição do rebanho, o quantitativo de fêmeas, em relação aos machos foi maior, entre 2011 e 2015 (Tabela 3). Quanto à categoria, por faixa etária, o grupo de fêmeas, acima de 36 meses, sempre predominou, essa faixa se estende até mais tarde, por terem vida útil reprodutiva mais longa, principalmente as matrizes em lactação. Enquanto os machos, o maior grupo está entre 13 a 24 meses, havendo decréscimo no quantitativo de cabeças devido adquirem peso ideal para abate e posterior comercialização. 
Tabela 3. Efetivo bovino do município de Rondon do Pará, por faixa etária, 2011 a 2015.

\begin{tabular}{ccccccccccc}
\hline & \multicolumn{4}{c}{ Fêmea (mês) } & \multicolumn{7}{c}{ Macho (mês) } & \multirow{2}{*}{ Total } \\
\cline { 2 - 8 } Período & $\mathbf{0 - 1 2}$ & $\mathbf{1 3 - 2 4}$ & $\mathbf{2 5 - 3 6}$ & $\mathbf{> 3 6}$ & $\mathbf{0 - 1 2}$ & $\mathbf{1 3 - 2 4}$ & $\mathbf{2 5 - 3 6}$ & $\mathbf{> 3 6}$ & \\
\hline 2011 & 25.285 & 32.203 & 33.411 & 124.151 & 26.816 & 36.169 & 33.630 & 34.694 & 346.359 \\
2012 & 32.831 & 31.865 & 35.000 & 108.605 & 36.419 & 33.958 & 36.769 & 18.674 & 331.121 \\
2013 & 34.712 & 31.761 & 37.241 & 113.081 & 37.765 & 36.438 & 35.815 & 37.157 & 363.970 \\
2014 & 31.792 & 30.199 & 29.335 & 135.684 & 36.805 & 35.938 & 31.430 & 33.903 & 365.086 \\
2015 & 27.255 & 34.173 & 29.210 & 132.155 & 33.772 & 40.311 & 28.814 & 38124 & 363814 \\
\hline
\end{tabular}

Fonte: ADEPARÁ (2015).

Os dados do IBGE (2015) mostram decréscimo de produção, número de vacas ordenhadas, produtividade, e preço do litro de leite nos últimos cinco anos em Rondon do Pará. A produção era de 18.604, em 2010, e caiu para 3.851, em 2015. Nesse mesmo período o número de vacas ordenhadas foi de 25.394 para 6.208, no entanto o impacto sobre a produtividade foi menor, de 732,61 para 620,33 1/vaca/ano. Quanto aos preços do litro de leite seguiram a mesma tendência passando de R\$2,11, em 2010, para R\$ 1,05, em 2015.

Esses dados mostram que a pecuária leiteira teve perda de desempenho no município e pode ter sofrido influência da expansão de outras atividades como da agricultura e silvicultura, com grandes extensões de áreas plantadas de grãos, principalmente soja, com aumento do plantio de 150 ha, em 2008, para 12.000 ha, em 2014; milho, de 3.150 ha, em 2008, para 4.000 ha, em 2014, e 11.000 ha de reflorestamento (IBGE, 2015).

\section{PROCESSAMENTO E COMERCIALIZAÇÃO}

O segmento à jusante da unidade de produção de leite é composto pelas atividades de transporte, processamento e beneficiamento, armazenamento e distribuição. Envolvem os canais de comercialização que, a partir de diversos agentes intermediários, conduz o produto até o consumidor final.

Existem dois laticínios que captam o leite produzido na região de Rondon do Pará, um tem o selo do Serviço de Inspeção Estadual (SIE) e outro de Serviço de Inspeção Federal (SIF). Existem dois modos de transporte do leite no município. No primeiro, o produto é armazenado em galões que ficam em frente às propriedades e um caminhão aberto leva o produto até o laticínio. O segundo modo envolve o uso de tanques de resfriamento, individual ou 
compartilhado por vários proprietários de uma vicinal, e o caminhão refrigerado coleta e transporta até a agroindústria.

Ressalta-se que não existe bonificação por parte da agroindústria pela qualidade e forma de armazenamento do produto, o que interfere diretamente na adequação à instrução normativa 62 (IN 62) que busca níveis de redução de Contagem de Células Somáticas (CCS) e Contagem Total Bacteriana (CTB), porém mais gradativa em termos de limite e com mais quatro anos para o atendimento do menor limite estabelecido para todo o País (BRASIL, 2011). O Ministério da Agricultura, Pecuária e Abastecimento (MAPA) publicou a IN 62, alterando a IN 51, e começou a vigorar em $1^{\circ}$ de janeiro de 2012 (BRASIL, 2002; BRASIL, 2011).

Quanto ao tamanho da empresa, o SEBRAE (2016) destaca dois critérios para estabelecer o porte empresarial, o faturamento e o número de empregados. Assim, microempresas são as que apresentam até 19 funcionários, pequena empresa entre 20 e 99, médias entre 100 e 499, e grandes com mais de 500 funcionários. Com base nestes critérios classificaram-se as duas empresas agroindustriais que atuam em Rondon do Pará. A primeira é uma microempresa com 15 funcionários, com tanque de processamento com capacidade de 20.000 litros de leite, e que capta leite de 90 propriedades com média de 80 litros de leite por dia, o que corresponde a apenas $36 \%$ da capacidade da empresa. A ociosidade é ainda maior, principalmente, nos períodos de agosto a setembro, quando a sazonalidade da produção de forragem implica em queda na produção leiteira.

A segunda, classificada como pequena empresa, possui 37 funcionários, com tanque de processamento com capacidade de 100.000 litros, mas capta apenas 40.000 litros, isso com coleta em propriedades no Maranhão e nos municípios vizinhos, como Abel Figueiredo e Bom Jesus do Tocantins, pois a produção local não consegue suprir a capacidade da indústria.

Diversos são os derivados de leite produzidos pelas empresas, como leite pasteurizado, requeijão, manteiga e queijo com destaque para o queijo mozarela e o iogurte que são os principais produtos das empresas de laticínios do estado do Pará (MATOS e SANTANA, 2015). Isso se deve ao fato do queijo mozarela não exigir leite de alta qualidade no processo de fabricação, além de apresentar mercado consumidor garantido.

O leite captado pelas indústrias que atuam na região é de baixa qualidade, principalmente, com relação à contagem de células somáticas (CCS) e contagem bacteriana total (CBT). Isso está muito associado a aspectos culturais dos produtores rurais que oferecem resistência às inovações tecnológicas para melhorar e qualificar a sua produção, além de ser uma região carente de informação e mão de obra qualificada, ter problemas com a regularização fundiária, estradas de péssima qualidade, deficiente distribuição de energia elétrica, falta de assistência técnica e o 
grande número de queijarias informais que exercem concorrência predatória com a agroindústria legalizada.

O leite e os derivados podem ser distribuídos por vários canais, de acordo com o porte da empresa processadora e da natureza dos produtos, o que reflete diretamente na embalagem utilizada e no estado físico. As formas de distribuição mais comuns são as vendas diretas pelas indústrias, através de vendedores ou representantes e as vendas por distribuidores ou atacados, e pelo varejo, com destaques para os supermercados (VARGAS; FIEGENBAUM, 2014).

O principal canal de distribuição em Rondon do Pará é a venda direta in natura para laticínios que atuam na região, que após processamento atendem o mercado local de leite pasteurizado e de derivados, distribuídos em supermercados, hotéis, padarias e restaurantes. Mas, grande parte do queijo mozarela produzido é comercializado para o mercado de lácteos do nordeste brasileiro.

Ainda existem os canais de produtos informais, na grande maioria queijarias nas propriedades rurais, que produzem queijo ou massa de queijo e repassam esse produto ao atravessador que pode atender diretamente as mesmas redes da indústria legalizada ou fornecer diretamente ao consumidor final, sendo um forte concorrente para a indústria.

Para o produtor de leite, os bezerros machos e as vacas de descarte entram como adicional na renda da família, considerados produtos de alto valor. O primeiro, oriundo de uma pecuária de dupla aptidão, é negociado com propriedades que trabalham com pecuária de corte, e o segundo comprado por frigoríficos ou açougues clandestinos.

\section{INSTITUIÇÕES E ORGANIZAÇÕES DE APOIO A PRODUÇÃO}

No município de Rondon do Pará, o ambiente institucional e organizacional é configurado pelos seguintes atores:

1) Secretaria Municipal de Educação: Compete a esta secretaria a distribuição da merenda escolar que apresenta demanda mensal é de 200 fardos de $10 \mathrm{~kg}$ de leite em pó e 48.000 litros de leite longa vida, para um total de 8.879 alunos. Essa demanda poderia ser atendida pelos produtores de leite locais, tendo em vista que, em 2016, houve o repasse do governo federal de $\mathrm{R} \$ 386.240,00$ para este fim e no mínimo 30\% ( $\mathrm{R} \$ 115.872,00)$ deveria ser alocado na aquisição de produtos da agricultura familiar (BRASIL, 2009). Esta secretaria atende essa exigência e emprega $38,76 \%$ desses recursos na aquisição de alimentos produzidos pela agricultura familiar, entretanto, apenas de produtos vegetais, o que poderia ser estendido para produtos de origem animal, a exemplo dos lácteos, caso houvesse um laticínio e/ou cooperativa que oferecesse o produto com a quantidade e especificações exigidas. 
2) Secretaria Municipal de Ciência, Tecnologia e Meio Ambiente: A sua principal responsabilidade é a adequação do município aos princípios do Programa Municípios Verdes (PMV), cujo termo de ajuste de conduta (TAC) foi assinado em 2011. O objetivo do PMV é auxiliar a adequação dos municípios que compunham a lista dos maiores desmatadores da Amazônia, divulgada pelo Ministério do Meio Ambiente (MMA), em 2008. O PMV foi originado a partir de um "pacto de desenvolvimento sustentável", entre os municípios considerados críticos, ao longo do corredor da exploração madeireira e do desmatamento, denominado "arco do desmatamento". Para o funcionamento a secretaria municipal conta com uma equipe formada por um funcionário responsável pela elaboração do cadastro ambiental rural (CAR), um geógrafo, dois fiscais e um agrônomo.

3) Empresa Assistência Técnica e Extensão Rural do Estado do Pará (EMATER): Têm em seu escritório local, cinco técnicos agrícolas e três engenheiros agrônomos. Essa instituição presta serviços especializados na área de ciências agrárias e humanas, difunde conhecimento e informações técnicas no meio rural. Além disso, desenvolve projetos para obtenção de crédito rural, associado ao Programa Nacional de Fortalecimento da Agricultura Familiar (PRONAF), junto ao Banco do Brasil e ao Banco da Amazônia.

4) Agência de Defesa Agropecuária do Estado do Pará (ADEPARÁ): Exerce importante atuação nos programas sanitários de Erradicação da Febre Aftosa (PNEFA) e Controle e Erradicação da Brucelose e da Tuberculose Animal (PNCEBT), com resultados expressivos. Em 2007, contribuiu para que a região centro-sul do Pará fosse considera livre de febre aftosa com vacinação e, em 2014, para que esse status avançasse para o estado inteiro. Em Rondon do Pará, o escritório local possui quadro técnico composto por um médico veterinário, três técnicos agrícolas, e um gerente. A agência relata que no município existem 1.700 propriedades e que nos dois últimos anos o rebanho bovino se manteve estável mesmo com o aumento significativo das áreas de agricultura principalmente com soja e milho, e que está ocorrendo uma intensificação em termos de tecnologia nas áreas de pecuária.

A cadeia produtiva do leite conta com a atuação de uma associação de produtores, a Associação de Produtores Amigos do Leite (AMILEITE) e dois sindicatos, o Sindicato dos Trabalhadores e Trabalhadoras Rurais (STTR) e o Sindicato dos Produtores Rurais.

5) Associação de Produtores Amigos do Leite (AMILEITE): A associação reúne 25 produtores com o objetivo de obter melhores condições de aquisição de insumos junto aos fornecedores e lojistas, e melhores vendas de seus produtos junto às agroindústrias.

6) Sindicato dos Trabalhadores e Trabalhadoras Rurais - STTR: Essa instituição representa a agricultura familiar e o trabalhador rural. O município apresenta dez assentamentos com 
aproximadamente três mil famílias assentadas, o que evidencia o crescimento significativo da agricultura familiar. Para a instituição, os entraves para o crescimento das atividades agropecuárias são: a dificuldade de contratação de mão de obra, o êxodo rural, o envelhecimento da população do campo, as inadimplências no pagamento de crédito rural, a falta de assistência técnica e a falta de uma gestão municipal comprometida com a agricultura familiar. Atualmente algumas culturas como a soja, o milho e o eucalipto expandem-se ocupando cada vez mais os espaços que antes eram da pecuária leiteira, e consequentemente provocam a diminuição desta atividade.

7) Sindicato dos Produtores Rurais: Essa instituição representa os grandes produtores rurais de Rondon do Pará. A percepção da instituição é de que o município tem como base de sua produção leiteira a agricultura familiar, onde os produtores têm a cultura de trabalhar sozinhos e deixam de formar cooperativas para auxiliariam o desenvolvimento da atividade. A principal dificuldade encontrada pela pecuária leiteira no município é a falta de assistência técnica. $\mathrm{O}$ sindicato tem um papel importante no desenvolvimento e manutenção da atividade leiteira no município, com a organização do tradicional Torneio Leiteiro, que ocorre há 16 anos durante a EXPORONDON, esta competição motiva os produtores e divulga a atividade junto à sociedade.

8) Banco da Amazônia e Banco do Brasil: São as instituições que financiam projetos dos produtores rurais no município. A agência local do Banco da Amazônia, criada em outubro de 2006, exige para financiar projetos agropecuários da área o cadastro ambiental rural (CAR). Atualmente financia com recurso do Fundo Constitucional de Financiamento do Norte (FNO) projetos para pecuária leiteira para aquisição de animais, instalações e benfeitorias e aquisição de máquinas e equipamentos. Em 2014, foram concedidos cerca de R\$ 7 milhões em crédito de fomento para agricultura familiar, envolvendo várias atividades. O Banco do Brasil financia atividade leiteira através dos programas Mais Alimentos e PRONAF direcionados para o desenvolvimento da agricultura familiar e, em 2014, foram liberados $\mathrm{R} \$ 4$ milhões para esta finalidade. Essas instituições consideram que a bovinocultura leiteira do município tem sérios limitantes que prejudicam o seu desenvolvimento, entre os quais se destacam a qualidade do rebanho, que em sua maioria é de aptidão mista, falta de assistência técnica para elaboração de projetos e alta taxa de inadimplência.

\section{CONCLUSÃO}

No município de Rondon do Pará, apesar de o efetivo bovino apresentar relativa estabilidade nos últimos anos, os dados mostram que a pecuária leiteira perde espaço para outras 
atividades agropecuárias, sobretudo com a expansão das atividades de agricultura e silvicultura, com grandes extensões de áreas plantadas de grãos, principalmente soja e milho e reflorestamento com eucalipto e outras essências florestais.

No que diz respeito ao processamento e beneficiamento pela agroindústria, a qualidade do produto é um dos principais entraves para o desenvolvimento da cadeia. Também é evidente o envelhecimento das populações do meio rural, mão de obra escassa e pouco qualificada, regularização fundiária, estradas de péssima qualidade, deficiente distribuição de energia elétrica, falta de assistência técnica e o grande número de queijarias clandestinas.

O leite produzido em Rondon do Pará tem diversos canais de distribuição. O principal deles é venda direta in natura para laticínios que atuam na região, que após processamento atendem o mercado local de leite pasteurizado e de derivados, distribuídos em supermercados, hotéis, padarias e restaurantes, mas grande parte do queijo mozarela produzido é comercializado para o mercado de lácteos do nordeste brasileiro. Existe forte concorrência do mercado informal com distribuição de leite in natura e queijos diretamente aos pontos de venda e consumidor final.

Os resultados obtidos a partir das percepções dos principais atores dessa cadeia produtiva mostram que diversos fatores limitam o seu desenvolvimento. A persistência de sistemas de produção de baixo nível tecnológico implica em baixa produtividade e qualidade do produto final o que termina sendo reforçado pela falta de conhecimento, acompanhamento técnico, financiamento e de capacitação dos produtores que são elementos fundamentais para uma pecuária leiteira mais eficiente e sustentável.

\section{REFERÊNCIAS}

ADEPARÁ. Relatório da campanha de febre aftosa, primeiro semestre de 2016. Belém. ADEPARÁ, 2016.

BRASIL. Ministério da Agricultura, Pecuária e Abastecimento. Instrução Normativa ${ }^{\circ} 51$. Diário Oficial da União. Brasília (DF). 2002. Disponível em:< https://www.jusbrasil.com.br/diarios/529972/pg-11-secao-1-diario-oficial-da-uniao-dou-de-0205-2002>. Acesso em: 23 ago. 2016.

BRASIL. Ministério da Educação. Fundo Nacional de Desenvolvimento da Educação. Programa Nacional de Alimentação Escolar. Lei federal n 11.947. Diário Oficial da União. Brasília: FNDE, 2009. Disponível em: < http://www.planalto.gov.br/ccivil_03/_ato20072010/2009/lei/111947.htm>. Acesso em: Acesso em: 23 ago. 2016. 
BRASIL. Ministério da Agricultura, Pecuária e Abastecimento. Instrução Normativa no 62.

Diário Oficial da União, Brasília (DF). 2011. Disponível em:<

http://extranet.agricultura.gov.br/sislegis-

consulta/consultarLegislacao.do?operacao=visualizar\&id=2851>. Acesso em: Acesso em: 23 ago. 2016.

IBGE. Instituto Brasileiro de Geografia e Estatística. Pesquisa Pecuária Municipal. Rio de Janeiro, v. 43, p.1-49, 2015.

MATTOS, C. A. C., SANTANA, A. C. A agroindústria de leite no estado do Pará. In:

LOURENÇO JÚNIOR, J. B.; SANTOS, M. A. S (Org.). Qualileite: Qualidade e tecnologia na cadeia produtiva do leite no estado do Pará. Belém: Marques Editora, 2015. Cap. 9, p.225-258.

NORONHA, G. N.et al. Caracterização da cadeia produtiva da pecuária de corte no município de Tailândia, estado do Pará. Amazônia: Ciência \& Desenvolvimento. v. 11, n. 21, 2015.

SANTANA, A. C., AMIN, M. M. Cadeias produtivas e oportunidades de negócios na Amazônia. Belém: UNAMA, 454p, 2002.

SANTOS, M. A. S.; SANTANA, A. C. A cadeia de valor da mandioca no município de Portel. In: SANTANA,A.C.de (Org.). Mercado, cadeia produtiva e desenvolvimento rural na Amazônia. Belém-PA: Edufra, 2014, v. 1, p. 253-282.

SANTOS, M. A. S.et al. Avaliação do nível tecnológico da pecuária leiteira no estado do Pará. Amazônia: Ciência \& Desenvolvimento. v. 9, n. 18, p. 79-96, 2014a.

SANTOS, M. A. S.et al. Determining factors of modernization of dairy farming in the Brazilian Amazon. Livestock Research for Rural Development, v. 26, n. 10, p. 180, 2014b.

SEBRAE- SERVIÇO BRASILEIRO DE APOIO ÀS MICRO E PEQUENAS EMPRESAS.

Critérios e conceitos para a classificação de empresas. Disponível em:

http://www.sebrae.com.br/uf/Goias/indicadosres-da-mpr/classificação-empresaria. Acesso em: 23 de Ago. 2016.

SOARES, S. O.et al. Perfil dos produtores de leite e caracterização técnica das propriedades leiteiras dos municípios de Rondon do Pará e Abel Figueiredo, estado do Pará. Veterinária em Foco, v.10, n.2, p. 159-168, 2013.

VARGAS, E. S., FIEGENBAUM, J. A evolução da agroindústria de laticínios no Brasil com base nos indicadores de estrutura, conduta e desempenho. Teoria e Evidência Econômica. v. 20, n. 42, p. 9-41, 2014.

VIANA, G., FERRAS, R. P. R. A cadeia produtiva do leite: um estudo sobre a organização da cadeia e sua importância para o desenvolvimento regional. Revista Capital Científico. v. 5, n. 1, p. 23-40, 2007. 